\title{
ADDITIONS OF ALLYLBORONATES TO SULFENIMIDES
}

Peter G.M. Wuts* and Yong Woon Jung

Department of Chemistry, University of Michigan, Ann Arbor, Michigan 48109

Summary: The addition of allylboronates to sulfenimines gives homoallyisulfenamides which are potentially versatile intermediates for alkaloid synthesis.

Although several methods have been explored for the addition of organometallics to imines and their derivatives most procedures are accompanied by low yields and/or undesirable side reactions (1). Earlier, others have reported on the addition of allylboronates (2) and allylboranes $(3,4)$ to imines. We now wish to report our results on the addition of allylboronates to sulfenimines (5) to give sulfenamides which have considerable potential in the synthesis of alkaloids.

Thus refluxing a mixture of pinacol allylboronate $\underline{2}$ and the sulfenimine 1 in toluene for 3 to 11 days gave clean conversions to the desired adducts $\underline{5}$ (Table I). The sluggishness of the reaction is clearly undesirable and may be attributed to the nature of the transition state 4 . The trans configuration of aldimines $(5 b, 6)$ forces the $R$ group to exist in an axial orientation in the transition state if we<smiles>[R]C=[W]</smiles>

1<smiles>[R]C1([R])OB(CC=C)OC1([R])[R]</smiles>

$$
\begin{aligned}
& 2 R^{3}=M e \\
& 2 R^{3}=H
\end{aligned}
$$

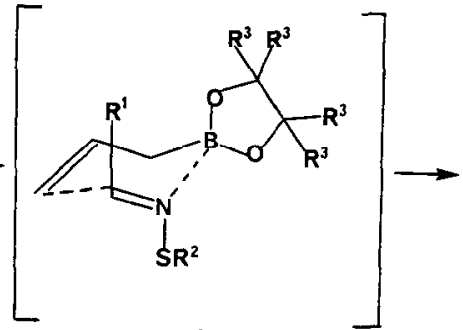

4<smiles>[R]C([R1])CC=C</smiles>

$\underline{5}$

Address correspondence to this author at the Upjohn Co. 1500-230-4, Kalamazoo, MI 49001. 
Table I

\begin{tabular}{|c|c|c|c|c|c|}
\hline Entry & $\mathrm{R}^{1}$ Sulfenimin & ne $\frac{1}{R^{2}}$ & $\underset{\mathrm{R}^{3}}{\text { Boronate }}$ & Rxn time & * yield sa \\
\hline 1 & $\mathrm{Me}-$ & $\mathrm{Ph}$ & $\mathrm{Me}$ & 3 days & 88 \\
\hline 2 & $\mathrm{CH}\left(\mathrm{CH}_{3}\right)_{2}^{-}$ & $\mathrm{m}-\mathrm{NO}_{2}-\mathrm{Ph}$ & Me & 4 days & 80 \\
\hline 3 & $\mathrm{C}_{4} \mathrm{H}_{9}-$ & $1 "{ }^{2}$ & $\mathrm{Me}$ & $40 \mathrm{~h}$ & 83 \\
\hline 4 & $\mathrm{PhSCH}_{2} \mathrm{CH}_{2}-$ & $"$ & $\mathrm{Me}$ & $22 \mathrm{~h}$ & 83 \\
\hline $5 \mathbf{a}$ & $\mathrm{BnOCH}_{2} \mathrm{CH}_{2} \mathrm{CH}_{2}-$ & $"$ & Me & $46 \mathrm{~h}$ & 77 \\
\hline $5 b$ & & $"$ & $\mathrm{H}$ & $4 h$ & 76 \\
\hline $6 a$ & $\mathrm{Ph}-$ & $"$ & $\mathrm{Me}$ & 11 days & 89 \\
\hline $6 \mathrm{~b}$ & $n$ & $"$ & $\mathrm{H}$ & $28 \mathrm{~h}$ & 95 \\
\hline $7 \mathbf{a}$ & & $"$ & Me & 9 days & 94 \\
\hline $7 \mathrm{~b}$ & & $"$ & H & $23 \mathrm{~h}$ & 92 \\
\hline
\end{tabular}

a Yields refer to isolated chromatographically pure material. All new compounds gave satisfactory analytical data, NMR, and IR spectra.

invoke the usual zimmerman-Traxler 6-centered transition state (7). Examination of molecular models of the TS reveals that the thioaromatic of the sulfenimine suffers considerable interaction with the bulky pinacol group. Therefore by changing to a smaller group such as ethylene this interaction is reduced and the rate of reaction should increase. Indeed this is observed. The use of the ethylene glycol allylboronate $\underline{3}$ results in a 10 -fold increase in the reaction rate in comparable ylelds (entries $\underline{5 b}, \underline{6 b}, \underline{7 b}$ ). This result further confirms that the reaction proceeds by initial complexation of the imine to boron followed by allyl transfer as postulated for the related condensation with aldehydes ( 8 ).

Table I gives the results for a variety of sulfenimines. In general, the reaction proceeds smoothly and in high yield and represents one of the few available methods for efficiently adding the allyl group to imine derivatives. Moreover, this methodology nicely compli- 
ments the existing allylborane methodology based on simple imines in that sulfenamides are readily hydrolyzed to primary amines (9) whereas imine based chemistry is generally restricted to the syrithesis of secondary amines.

We have also found that the addition of gaseous $\mathrm{HCl}$ to the crude reaction mixture prior to work-up gives clean conversion to the sulfides $\underline{6}$ and $\underline{7}$. The reaction proceeds by initial formation of phenyl sulfenyl chloride which then adds to the olefin (9). The recent report by Kamatani (10) on the conversion of these adducts to pyrrolidines $\underline{8}$ further enhances the utility of this overall process.

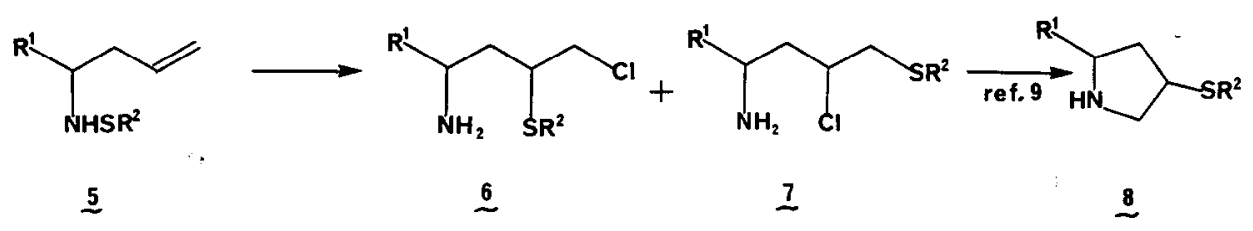

Sample Experimental Procedure: A mixture of allylboronate (11) $(7.50 \mathrm{mmol})$ and sulfenimine $(5.0 \mathrm{mmol})$ in $10 \mathrm{~mL}$ of toluene was refluxed under argon until TLC indicated complete reaction. The mixture was cooled to room temperature and treated with $7.50 \mathrm{mmol}$ of triethanol amine $(3.0 \mathrm{M}$ in acetone) which produced a fine white precipitate. After stirring the mixture overnight, the solids were removed by filtration through celite and the product chromatographed on silica gel or alumina with ethyl acetate/hexane. Chromatography on alumina is recommended since partial hydrolysis of the sulfenamide sometimes occurs during silica gel chromatography(12). 


\section{References}

1. J. Barleunga, F. T. Fanans, J. Viliamaua and M. Yus, J. Org. Chem., 47, 1560 (1982); G. Courtois and L. Miginiac, J. organometal. Chem.. 69, 1 (1974); J. Thomas, Bul1. Soc. Chim. Fr., 1296, 1300 (1973); ibid. , 209 (1975); J. Thomas, E. Henry-Basch and P. Freon, Bul1. Soc. Chim.Fr., 109 (1969); H. I. Sheverdina and K. A. Kocheshkov, "Methods of Elemento-organic Chemistry," Vol. 13, The organic Chemistry of $Z i n c$ and Cadmium, North-Holland, Amsterdam, 1967; L. Miginiac and B. Maccize, Bull. Soc. Chim.Fr., 3832 (1968); J. Huet, ibid., 952 (1964); C. Bouchoule and P. Miginiac, C. R. Acad. Sci. Ser. C., 266, 1614 (1968); M. W. Rathke, Org. Reactions, 22, 423 (1974); R. Arous-ohtara, J. L. Moreau and M. Graudemar, J. SoC. Chim. Tuni s, 3,1 (1980); B. Mauze, J. Organometal. Chem., 202, 233 (1980); C. H. Meltz and R. A. Volkmann, Tetrahedron Lett., 24, 4503 (1983); M. Wada, Y. Sakurai and K. Akiba, Tetrahedron Lett., 25, 1079 (1984); F. A. Davis and $P$. A. Mancinelli, J. Org._Chem. 42, 398 (1977).

2. R. W. Hoffmann, G. Eichler and A. Endesfelder, Liebigs Ann. Chem., 2000 (1983).

3. A. Miller and $W$. Gregor, Monatsh., 105, 684 (1974).

4a. Y. Yamamoto, T. Komatsu, K. Maruyama J. Org. Chem., 50, 3115 (1985); b. Y. Yamamoto, T. Komatsu, K. Maruyama, J._Am. Chem.Soc., 106, 5031 (1984).

5. Preparation of sulfenimines: a. F. A. Davis, W.A.R. Slegeir, S.Evans, A.Schwartz, D. L. Goff and R. Palmer; J. Org. Chem., 38, 2807 (1973); b. F. A. Davis and P.A. Mancinelii; J.org. Chem., 43, 1797 (1978); C. B. P. Branchard; J. Org._Chem., 48, 3531 (1983); ibid., $3588(1983)$.

6. C. G. McCarty In "The Chemistry of the Carbon-Nitrogen Double Bond", Patai, S. Ed., Interscience London 1970 p363.

7. See reference $4 a$.

8. For a review see R. W. Hoffmann, Angew. Chem. Int. Ed., 21, 555 (1982).

9. For a disclission of sulfenamide chemistry see: F. A. Davis, International J. Sulfur chem. 8,71 (1973).

10. T. Ohsawa, M. Ihara, K. Fukumoto and T. Kametani, J. Org. Chem., $\underline{48}, 3645(1983)$.

11. Allylboronates were prepared by the addition of allylmagnesium bromide to trimethylborate followed by ester exchange with either pinacol or ethylene glycol and distiliation of the product.

12. Acknowledgement is made to the National Institutes of Health and the National Science Foundation for their generous support.

(Received in USA 8 November 1985) 